Article

\title{
Single Layer Broadband Anti-Reflective Coatings for Plastic Substrates Produced by Full Wafer and Roll-to-Roll Step-and-Flash Nano-Imprint Lithography
}

\author{
Marieke Burghoorn ${ }^{1}$, Dorrit Roosen-Melsen ${ }^{1}$, Joris de Riet ${ }^{2}$, Sami Sabik ${ }^{2}$, Zeger Vroon ${ }^{1,3}$, \\ Iryna Yakimets ${ }^{2}$ and Pascal Buskens ${ }^{1,4}, *$
}

1 The Netherlands Organisation for Applied Scientific Research (TNO), De Rondom 1, 5612 AP Eindhoven, The Netherlands; E-Mails: marieke.burghoorn@tno.nl (M.B.); dorrit.roosen@tno.nl (D.R.-M.); zeger.vroon@tno.nl (Z.V.)

2 Holst Centre, High Tech Campus 31, 5656 AE Eindhoven, The Netherlands;

E-Mails: joris.deriet@tno.nl (J.D.R.); sami.sabik@tno.nl (S.S.); iryna.yakimets@ tno.nl (I.Y.)

3 Zuyd Hogeschool, Nieuw Eyckholt 300, 6419 DJ Heerlen, The Netherlands

4 DWI an der RWTH Aachen e.V., Forckenbeckstrasse 50, 52074 Aachen, Germany

* Author to whom correspondence should be addressed; E-Mails: pascal.buskens@ tno.nl; buskens@dwi.rwth-aachen.de; Tel.: +31-88-8662990; Fax: +31-88-8668847.

Received: 5 July 2013; in revised form: 14 August 2013 / Accepted: 19 August 2013 /

Published: 27 August 2013

\begin{abstract}
Anti-reflective coatings (ARCs) are used to lower the reflection of light on the surface of a substrate. Here, we demonstrate that the two main drawbacks of moth eye-structured ARCs - i.e., the lack of suitable coating materials and a process for large area, high volume applications - can be largely eliminated, paving the way for cost-efficient and large-scale production of durable moth eye-structured ARCs on polymer substrates. We prepared moth eye coatings on polymethylmethacrylate (PMMA) and polycarbonate using wafer-by-wafer step-and-flash nano-imprint lithography (NIL). The reduction in reflection in the visible field achieved with these coatings was $3.5 \%$ and $4.0 \%$, respectively. The adhesion of the coating to both substrates was good. The moth eye coating on PMMA demonstrated good performance in three prototypical accelerated ageing tests. The pencil hardness of the moth eye coatings on both substrates was <4B, which is less than required for most applications and needs further optimization. Additionally, we developed a roll-to-roll UV NIL pilot scale process and produced moth eye coatings on polyethylene terephthalate (PET) at line speeds up to two meters per minute. The resulting coatings showed a good replication of the moth eye structures and,
\end{abstract}


consequently, a lowering in reflection of the coated PET of $3.0 \%$.

Keywords: anti-reflective; coating; nano-imprint lithography; roll-to-roll; durability; moth eye

\section{Introduction}

Anti-reflective coatings (ARCs) are used to lower the reflection of light on the surface of a substrate and enhance the transmission [1,2]. The areas of application for ARCs can be divided in two main categories: applications in which the ARC is used for aesthetic purposes and applications in which the ARC is used to improve the efficiency of devices. Examples of the first category are eyeglasses, museum and picture glass and displays [1-4]. Examples of the second category are lenses and devices that convert light to electricity and vice versa, like photovoltaic (PV) cells or light-emitting diodes (LEDs) in which the ARC contributes to a more efficient in- and out-coupling of light, respectively [1,2,5-10]. Much attention has been paid in recent literature to the use of ARCs in such solar and lighting devices [11]. Examples of improved in- and out-coupling of light through the use of ARCs on the device cover can be found for silicon, thin film and organic solar cells [5-7] and in lighting devices, like LEDs and their organic counterparts, OLEDs [8].

Three main coating concepts exist to lower the reflection and increase the transmission of a substrate. Multilayer stacks with alternating thin layers of a high and low refractive index can be used to create an interference filter [9]. They can be produced by vacuum/vapor deposition technologies, like sputtering or chemical vapor deposition (CVD), or by wet processing, e.g., using sol-gel chemistry [10]. The principle is based on destructive interference of the reflected light at the interfaces of the thin films in the multilayer stack. These coatings are typically robust and durable, but relatively expensive, due to the multiple coating and-in case of sol-gel coatings-curing steps; depending on the optical requirements of the ARC, the designs of two and more layers are reported to fine tune the optics $[1,2,11-14]$. These multi-layer interference filters are highly sensitive to process variations, like coating thickness and variations in refractive index. The optical performance can be tailored for specific needs, but is strongly dependent on the angle of incidence, since the optical path length in the layer stack increases with increasing angle of incidence. Multi-layer ARCs are applied to glass and polymeric substrates and have been on the market for several decades. Multi-layer ARCs are typically applied in high end markets in which the coating represents a high value. Examples of such markets are displays and picture and art glazing.

Secondly, an ARC can be realized using a coating of quarter wavelength thickness and a refractive index of $n=\sqrt{n_{s} \times n_{0}}$, with $n_{s}$ as the refractive index of the substrate and $n_{0}$ as the refractive index of the medium [1,2,15-17]. In the case of typical transparent polymeric substrates or glass with a refractive index of about 1.5 and air as medium, the ideal coating has a refractive index of 1.225 . In order to lower the refractive index of a coating to that level, porosity has to be introduced in the coating material [1,2,15-17]. This type of quarter wavelength coating can be applied in one processing step and is, therefore, typically more cost-efficient than a multi-layer interference stack. The optical properties of such coating can be tuned; the reflection curve is typically V-shaped. Hence, a quarter 
wavelength ARC normally has a very intense reflection color and lacks broad-band anti-reflective properties. Additionally, the porosity in the system can make the coating mechanically less robust than multi-layer stacks. Furthermore, depending on the type, arrangement and accessibility of the porous structure, they can be susceptible to contamination. Porous quarter wavelength ARCs are commercially available. Quarter wavelength coatings are typically applied in markets in which the value of the coating is low to medium. Examples of such markets are solar cell covers and cover materials for LEDs and OLEDs.

The third coating concept is so-called nanostructured graded-index coatings [1,2]. The nanostructures in such coatings create a gradient in the refractive index normal to the substrate surface. This graded refractive index increases from the refractive index of the medium, in most cases, air, to that of the substrate. Moth eye nanostructures are the most common example for this technology [18-23]. The resulting coatings have broadband anti-reflective properties. Angular dependence of the reflection is for this type of coating very low, and the color neutrality is good to excellent. However, the decreased mechanical strength due to the nanostructured top coat can be a disadvantage.

Graded-index, moth eye ARCs can be made using, e.g., nano-imprint lithography (NIL). NIL was developed in the mid-nineties as a technology for producing micro- and nano-structured surfaces [24-33]. In this process, a nanostructured mold is used and either pressed into a softened polymeric surface (thermal NIL) or a wet UV-curable resist layer (step-and-flash NIL). In case of thermal NIL, the substrate is typically heated to about $50{ }^{\circ} \mathrm{C}$ above its glass transition temperature, the mold is pressed into the heated substrate surface and, after cooling, the mold is removed, leaving the polymer surface with a negative copy of the structure of the mold. In the case of step-and-flash NIL, a nanostructured mold is used and pressed into a wet, UV-curable resist. Then, the coating is cured through exposure to UV light, and after de-molding, the negative copy of the mold's structure is left in the UV-cured coating layer. In the case of step-and-flash NIL, a positive copy of the mold can also be transferred to the UV-cured resist using a two-step procedure: transfer of the mold structure to a polymeric replica and transfer of the polymeric replica structure to the UV-curable resist. Both process variants are used to make micro- or nano-structured layers for use in a variety of devices and applications, e.g., devices for bio- and chemical sensing, transistors, random access memory patterns and integrated circuits [34-42]. In addition, NIL is often used to create nanostructured surfaces with an optical functionality [43-49], including moth eye ARCs [23,50-52].

Currently, however, moth eye ARCs are not commonly used in large-scale applications. The main reasons for this are the lack of suitable liquid coating materials, which are qualified for this application, and the lack of a simple, low-cost, high-volume, large-scale application process. Most commercially available coating materials_-(imprint) resists - are designed for subtractive lithography processes in which the resist is used for structuring silicon wafers and does not end up in the final product [34-42]. Hence, typical resist materials are not designed for permanent application on substrates and, depending on the application, typically lack part of the required properties. In spite of a variety of studies performed in the past few years [53-61], NIL is not yet commonly used for large area, high-volume applications.

This article shows experimental results demonstrating the potential to eliminate both disadvantages to a large extent. This enables cost-efficient and large-scale production of durable nanostructured moth eye-type ARCs on polymer substrates. 


\section{Results and Discussion}

\subsection{ARCs Produced by Full Wafer Step-and-Flash NIL}

To produce moth eye-type ARCs by full wafer step-and-flash NIL, we used the commercially available HT-AR-09 mold from Holotools. The mold was replicated in a hard polydimethylsiloxane (h-PDMS). Using the h-PDMS replicas, we made imprints in the commercially available UV-curable resist, Ormocomp, which has a refractive index of 1.535 at $500 \mathrm{~nm}$ and is available from Microresist Technology. This resist has been specifically designed for use in NIL. The imprints in the resist were made using the Nanoimprint Technology Platform from NIL Technology. The h-PDMS replica is pressed into the photosensitive coating material, which was applied using a roll bar, and cured with UV light through the replica. The approximate layer thickness of the Ormocomp coating is $15.4 \mu \mathrm{m}$. Finally, the h-PDMS replica is removed. The resulting coating layer has a moth eye structure identical to that of the HT-AR-09 mold. The residual layer thickness is about $15 \mu \mathrm{m}$. The residual resist layer can serve as a hard coat underneath the ARC. For regular single layer ARCs, the process involves two coating and curing steps: application of a transparent hard coat on the polymer substrate, curing of the hard coat, application of the ARC on the hard coat and curing of the ARC. Our process offers the potential to apply and cure the hard coat and top coat in one single step, which is a clear advantage over traditional single-layer ARCs on plastics.

\subsubsection{Replication and Imprint Process}

The HT-AR-09 mold has the following specifications: the grating is a hexagonal array with a pitch of $250 \mathrm{~nm}$, an average depth of $250 \mathrm{~nm}$ and a peak-to-peak distance of $300 \mathrm{~nm}$. The surface structure of the h-PDMS replicas and the moth eye coatings on polymethylmethacrylate (PMMA, $n=1.49$ ) made with these replicas are evaluated using Helium Ion Microscopy (HIM) and Atomic Force Microscopy (AFM). The results are displayed in Figure 1.

Figure 1. Helium Ion Microscopy (HIM) (left) and AFM (right) pictures of (a) h-PDMS replica; (b) Ormocomp on polymethylmethacrylate (PMMA).
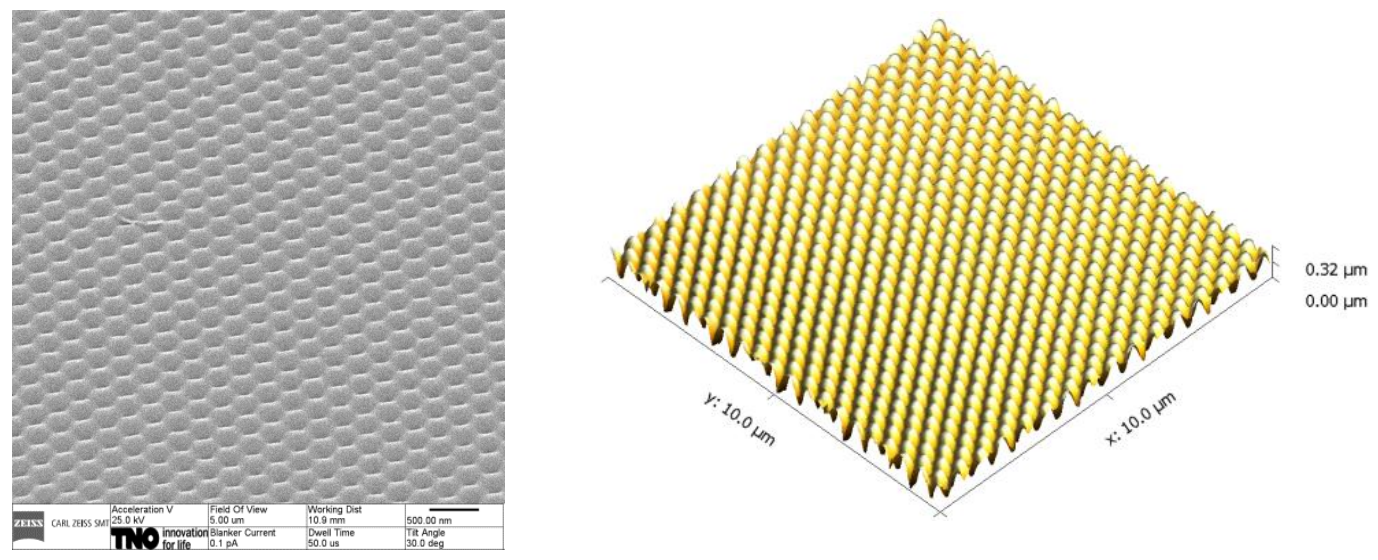

(a) 
Figure 1. Cont.
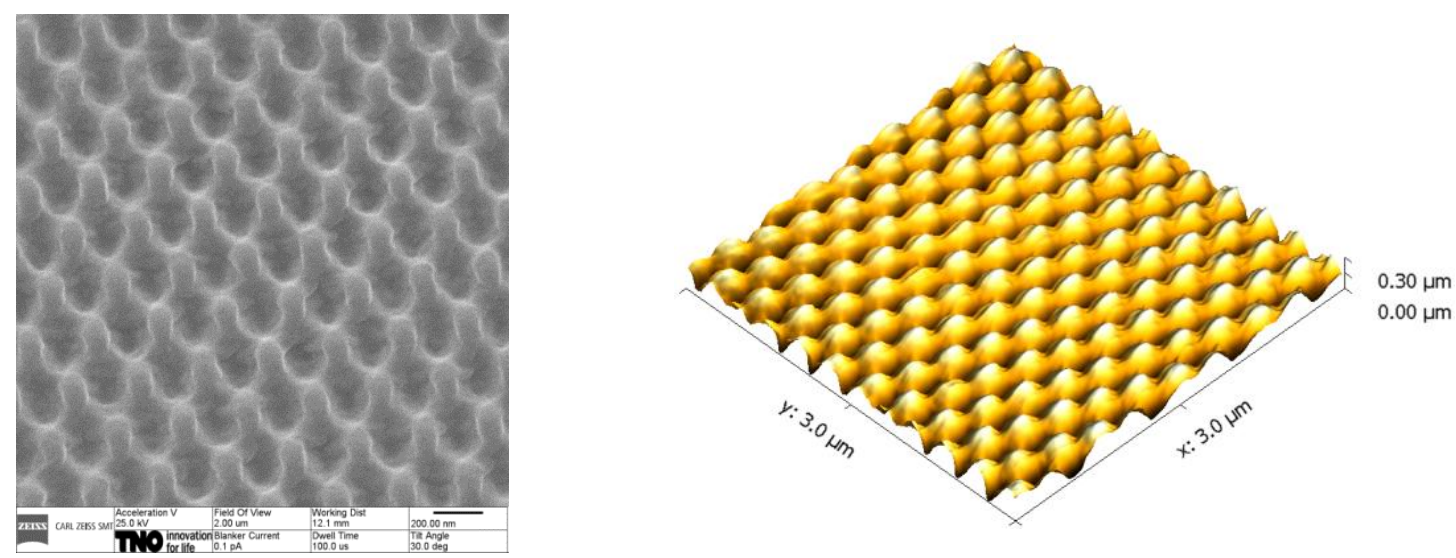

(b)

From the HIM and AFM images in Figure 1, we conclude that the surface nanostructure of the mold is well replicated in h-PDMS, and the surface nanostructure of the h-PDMS replica is well replicated in the Ormocomp coating. The pitch in lateral dimensions is $250 \mathrm{~nm}$ both for the h-PDMS and the moth eye-structured Ormocomp coating, which matches the original dimensions of the mold. The average structure depth for the structures on the h-PDMS replica and the Ormocomp coating is determined based on AFM data via analysis of a representative area of $1 \mu \mathrm{m}^{2}$ and displayed in Table 1. As demonstrated by the average depth of the structures on the h-PDMS replica, the replication mold to replica is perfect. The average depth of the structures in Ormocomp is $284 \mathrm{~nm}$. Although not perfect, the quality of the imprint from replica to coating is very good.

Table 1. Maximum depth and lateral pitch based on Atomic Force Microscopy (AFM) measurements. h-PDMS, hard polydimethylsiloxane.

\begin{tabular}{ccc}
\hline Material & Lateral pitch $(\mathbf{n m})$ & Average depth $(\mathbf{n m})$ \\
\hline Holotools mold & 250 & 300 \\
h-PDMS & 250 & 300 \\
Ormocomp & 250 & 284 \\
\hline
\end{tabular}

\subsubsection{Optical Properties of Moth Eye-Structured Ormocomp Coating}

Reflection and transmission measurements of single-side coated substrates are performed under near normal angle for the visible wavelength regime (VIS) between 425 and $675 \mathrm{~nm}$. The result for the moth eye-structured Ormocomp coating on PMMA is displayed in Figure 2, on polycarbonate (PC, $n=1.58$ ) in Figure 3.

The average reflection of PMMA in the visible spectrum is $7.6 \%$. Using the moth eye-structured Ormocomp coating on one side of the substrate, the reflection is lowered by $3.5 \%$. As displayed in Figure 2, the reflection of PMMA with a single-side imprinted coating layer is nearly constant in the visible spectrum, leading to broadband anti-reflective properties and a coating layer with a high degree of color neutrality. The average transmission of PMMA in the visible spectrum is increased by $3.4 \%$ after application of the ARC. 
Figure 2. Reflection and transmission of uncoated polymethylmethacrylate (PMMA) (red) and PMMA with moth eye-structured Ormocomp anti-reflective coating (ARC) (blue); dashed lines $=$ reflection, continuous lines $=$ transmission .

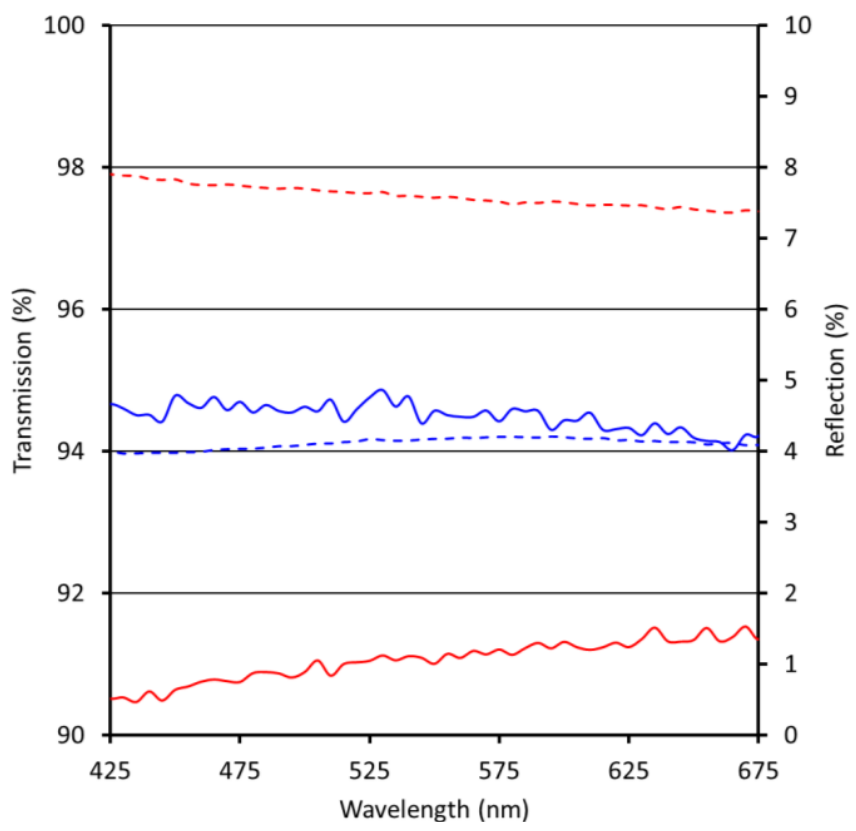

Figure 3. Reflection and transmission of uncoated polycarbonate (PC) (red) and PC with moth eye-structured Ormocomp ARC (blue); dashed lines = reflection, continuous lines $=$ transmission

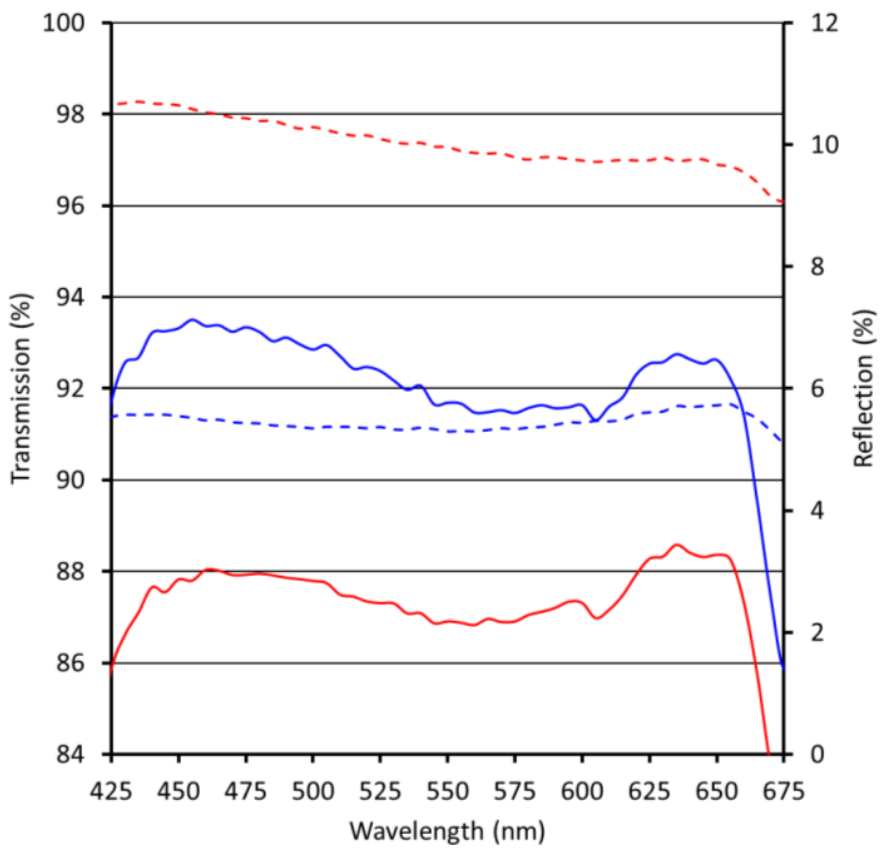

The average reflection for PC in the visible spectrum is $9.5 \%$. The reflection is lowered by $4.0 \%$ after application of the moth eye-structured Ormocomp coating on one side of the substrate. As displayed in Figure 3, the reflection of PC with a single-side imprinted coating layer is nearly constant in the visible spectrum, leading to broadband anti-reflective properties with a high degree of color neutrality. The transmission is increased by $3.9 \%$. 
Both on PMMA and PC, the achieved anti-reflective effect matches the requirements for most commercial applications. The high degree of color neutrality of the coating matches the typical specification for application on displays.

\subsubsection{Adhesion and Scratch Resistance}

To evaluate the adhesion of the Ormocomp coating to PMMA and PC, scotch tape tests were performed according to ISO2409:1992. For that purpose, pressure sensitive tape was applied to an area of the coating, which was cross-hatched with scratched lines. Adhesion is considered adequate if the coating is not pulled off by the tape when it is removed. For the moth eye-structured Ormocomp coating on both substrates, no coating material was removed during the scotch tape test, indicating good adhesion.

To evaluate the scratch resistance, pencil hardness tests according to ISO15184:1998 were performed for moth eye-structured and non-structured Ormocomp coatings on PC and PMMA. In all cases, three substrate samples were coated with Ormocomp resist, moth eye-structured using NIL and cured. Twenty-four hours after preparation, the pencil hardness of the coating was determined on three different positions per sample. Ergo, all values for pencil hardness are average values of nine measurements.

The pencil hardness is expressed as follows: the first value is the hardness of the hardest pencil that does not lead to a visible scratch on the surface of the coating; the second value is the hardness of the softest pencil that leads to a visible scratch on the surface of the coating. Approximate layer thickness of the Ormocomp coating without moth eye structures is $15.4 \mu \mathrm{m}$; the moth eye-structured Ormocomp coatings have a residual layer thickness of about $15 \mu \mathrm{m}$. The results are displayed in Tables 2 and 3 .

As displayed in Tables 2 and 3, the pencil hardness of the non-structured Ormocomp coating layer on PC is HB-F, which is higher than the pencil hardness of the uncoated substrate (2B-B). The moth eye-structured Ormocomp layer, however, has a significantly lower pencil hardness $(<4 \mathrm{~B})$. In case of PMMA as substrate, pencil hardness of the non-structured Ormocomp coating is similar to the pencil hardness of the uncoated substrate. For the structured Ormocomp layer, however, the pencil hardness is significantly lower $(<4 \mathrm{~B})$. There are two explanations for the decrease in pencil hardness upon structuring of the Ormocomp coating: (1) the surface nanostructure makes the coating much more sensitive towards scratches and (2) surface scratches on an ARC are much more visible than on a coating or substrate with about $8 \%$ reflection in the visible spectrum. Upon scratching of the nanostructured surface, the anti-reflective properties are (partly) lost, leading to a reflective scratch on a non-reflective surface. For most commercial applications of ARCs, a pencil hardness of $3 \mathrm{H}$ or higher is required. With the current pencil hardness, the coating can only be applied for non-touch applications. Hence, further work is needed to improve the scratch resistance of the moth eye-structured coating. Lowering the friction on the coating surface through use of slip agents or stabilization of the surface structure by a thin coating layer conformally deposited over the moth eye-structured Ormocomp may improve the scratch resistance. Options for surface modification, however, are restricted by the optical requirements needed to achieve the anti-reflective effect. 
Table 2. Pencil hardness test results of coatings on PC.

\begin{tabular}{ccc}
\hline Coating & Imprint & Undamaged-damaged pencil hardness \\
\hline Ormocomp & moth eye-structured & $<4 \mathrm{~B}$ \\
Ormocomp & non-structured & HB-F \\
Uncoated polycarbonate & $2 \mathrm{~B}-\mathrm{B}$ \\
\hline
\end{tabular}

Table 3. Pencil hardness test results of coatings on PMMA.

\begin{tabular}{ccc}
\hline Coating & Imprint & Undamaged-damaged pencil hardness \\
\hline Ormocomp & moth eye-structured & $<4 \mathrm{~B}$ \\
Ormocomp & non-structured & $2 \mathrm{H}-3 \mathrm{H}$ \\
Uncoated PMMA & $3 \mathrm{H}-4 \mathrm{H}$ \\
\hline
\end{tabular}

\subsubsection{Durability of the ARCs}

Accelerated ageing tests are performed on PMMA samples coated with non-structured and moth eye-structured Ormocomp to evaluate their durability. To get a first impression of the durability, three commonly applied accelerated ageing tests were performed: the damp heat test $\left(1000 \mathrm{~h}\right.$ at $85^{\circ} \mathrm{C}$ and $85 \%$ relative humidity), the thermal cycling test (200 cycles between $-40{ }^{\circ} \mathrm{C}$ and $85{ }^{\circ} \mathrm{C}$ ) and the humidity freeze test $\left(10\right.$ cycles between $85^{\circ} \mathrm{C}$ and $85 \%$ relative humidity and $\left.-40{ }^{\circ} \mathrm{C}\right)$. The results of these durability tests are shown in Table 4. All samples were prepared and tested in triplo. The values in Table 4 are average values.

Table 4. Effect of durability tests on absolute differences in average reflection (\%) in the visible-i.e., 425 to $675 \mathrm{~nm}$-regime. The change in reflection is presented in the table. $\left(\Delta R=R_{\text {after }}-R_{\text {before }}\right)$

\begin{tabular}{cccc}
\hline Uncoated/coated PMMA & $\begin{array}{c}\Delta \boldsymbol{R}[\%] \text { Damp heat 1000 } \\
\mathbf{h ~ 8 5}{ }^{\circ} \mathbf{C ~ 8 5 \% ~ R H}\end{array}$ & $\begin{array}{c}\Delta \boldsymbol{R}[\%] \text { Thermal } \\
\text { cycling 200 cycles } \\
\mathbf{- 4 0 / 8 5}{ }^{\circ} \mathbf{C}\end{array}$ & $\begin{array}{c}\Delta \boldsymbol{R}[\%] \text { Humidity } \\
\text { freeze } \mathbf{1 0} \text { cycles } 85^{\circ} \mathbf{C} \\
\mathbf{8 5 \%} \mathbf{~ R H ~ t o ~}-\mathbf{4 0}{ }^{\circ} \mathbf{C}\end{array}$ \\
\hline Uncoated PMMA & +0.10 & 0.00 & +0.07 \\
Ormocomp non-structured & +1.11 & +0.93 & +0.57 \\
Ormocomp moth & +1.16 & -0.08 & -0.32 \\
eye-structured & & & \\
\hline
\end{tabular}

The adhesion of Ormocomp to PMMA is very good; no delamination is observed after the tests. As demonstrated by the results displayed in Table 4, the reflection of the moth eye-structured Ormocomp coating stays nearly constant in the humidity freeze and thermal cycling tests, but increases by $1.16 \%$ in the damp heat test. Overall, these test results match the specifications for most applications of ARCs. In most cases, however, further specific ageing studies are required.

\subsection{Anti-Reflective Coatings Produced by Roll-to-Roll UV NIL}

To apply the above mentioned ARC to large area, high-volume applications, it is necessary to use a continuous coating and structuring process. For that purpose, we designed process equipment to apply and structure coatings on foil in a roll-2-roll (R2R) fashion. For a schematic representation and 
pictures of the R2R pilot equipment, see Figure 4 and 5, respectively. The system is fitted with a web tension management sub-system and an unwind-rewind sub-system. The business end is the imprint sub-system, which consists of a main drum and two contact rollers. The resist is deposited onto the web using a suitable R2R compatible technology, in casu droplet dispensing. The web and the resist are pressed onto the drum, which contains the moth eye-structured replica, by the first roller (imprint roller). In our specific case, the drum itself is not structured, but, instead, moth eye-structured PDMS replicas are fitted onto the drum. Hence, the resulting moth eye-structured ARC is not seamless. The resist is cured by high-powered UV LEDs, using the web tension to make sure the resist is cured in contact with the structure. After that, the release of the cured resist from the drum is facilitated by the second pressure roller, the delamination roller.

Figure 4. Roll-2-roll (R2R) imprint sub-system with the web direction from left to right: first, the non-structured, uncured resist on the web, the first roller, the drum containing the pattern with the UV LEDs below, the second roller and, finally, the structured, cured resist on the web.

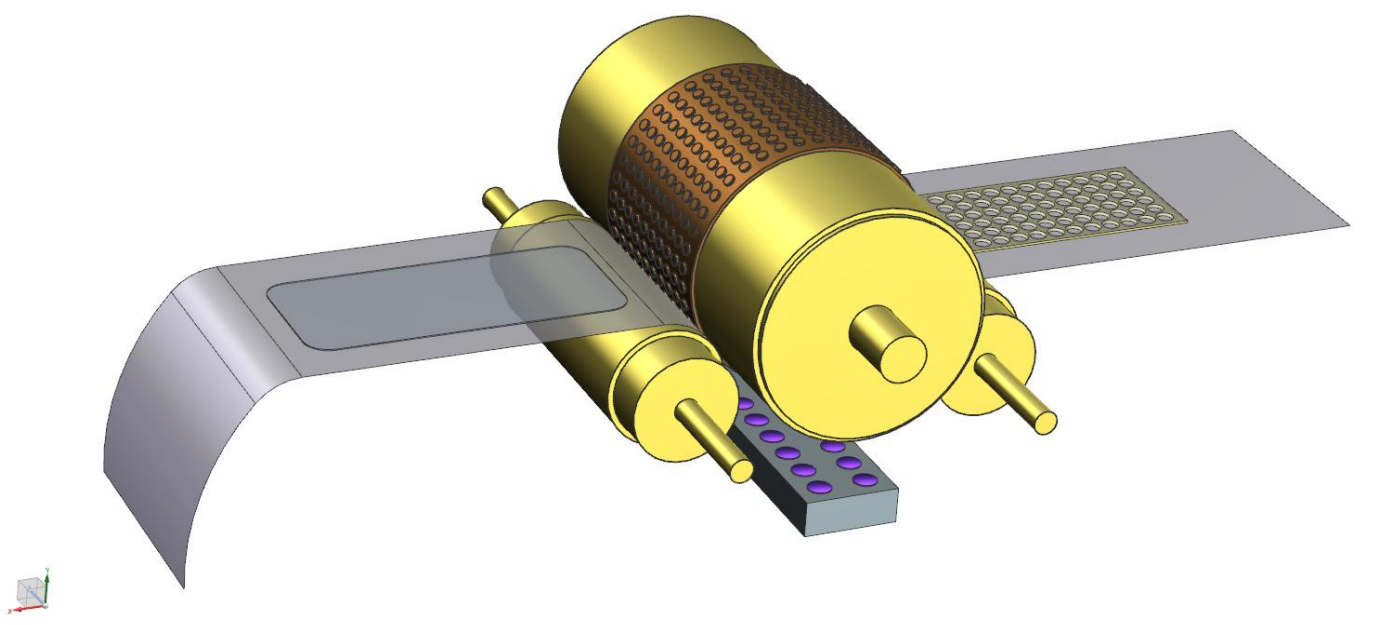

The tool has several adjustable parameters that are of influence to the imprint process, like line speed, web tension, UV intensity, imprint roller pressure (roller 1) and delamination roller pressure (roller 2). The tool is able to run at speeds in between zero, one and $3 \mathrm{~m} \cdot \mathrm{min}^{-1}$. The web width is $30 \mathrm{~cm}$; the drum has a circumference of $60 \mathrm{~cm}$. A UV blocking vented cover prevents any harmful gases from escaping to the environment (see Figure 5).

The tool is fitted with a droplet dispensing system. The thickness of the resist can be controlled by changing the pressure of the first roller, but is highly dependent on the viscosity of the resist. The tool is fitted with a high-power LED bar to cure the resist through the foil. The wavelength of the UV LEDs is $395 \mathrm{~nm}$.

In the experimental set-up for producing moth eye-structured Ormocomp layers, we used identical h-PDMS stamps as used in the wafer-by-wafer experiments. The stamp was mounted on the imprint drum. The resist was applied to the web using the above-mentioned droplet dispensing system. After optimization of the process parameters, we were able to produce moth eye-structured Ormocomp coatings on polyethylene terephthalate (PET, $n=1.57$ ). An SEM image of the moth eye-structured coating prepared at a line speed of two meters per minute using the above-mentioned R2R setup is displayed in Figure 6. 
Figure 5. Picture of the R2R nano-imprint lithography (NIL) pilot line.

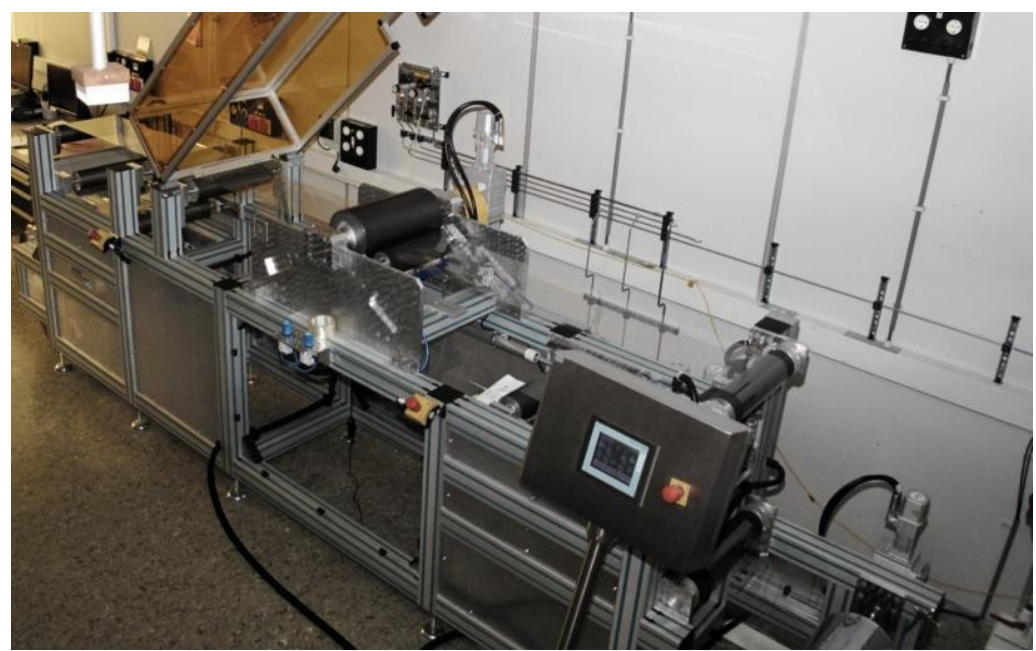

Figure 6. SEM image of moth eye-structured Ormocomp coating prepared using the R2R setup.

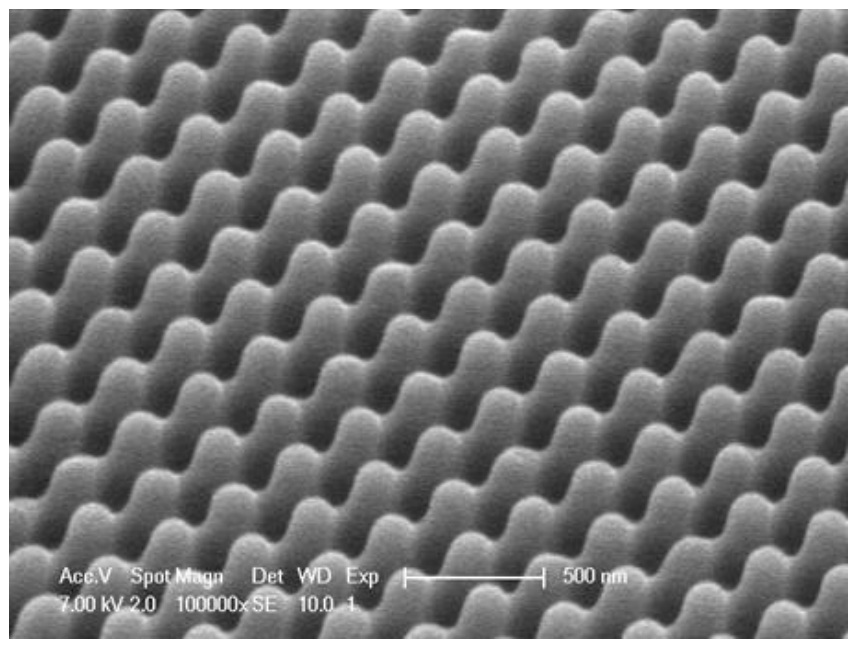

As displayed in this SEM image, the replication h-PDMS stamp to Ormocomp resist layer is very good. The average depth of the structures, as derived from cross-section SEM, is about $275 \mathrm{~nm}$. The VIS reflection of the PET foil decreased from $7.05 \%$ to $4.0 \%$; after application of the ARC, the transmission increased from $90.4 \%$ to $93.3 \%$. The residual layer thickness of this sample was about $30 \mu \mathrm{m}$.

The cross-hatch adhesion test showed good adhesion of the coating to the substrate. The pencil hardness was <4B. Ergo, we were able to efficiently process Ormocomp on the R2R setup, displayed in Figures 4 and 5. At a line speed of two meters per minute, we were able to properly replicate the structure of the h-PDMS stamp in the Ormocomp coating, leading to a decrease in the VIS reflection of $3.0 \%$.

\section{Experimental Section}

\subsection{Materials and Equipment}

The substrate materials were $3 \mathrm{~mm}$ Lexan 9030 polycarbonate from Sabic and $2 \mathrm{~mm}$ Acrylite Solar IM20 polymethylmethacrylate from Evonik. PET foil was obtained from AGFA (125 $\mu$ m thickness). 
The HT-AR-09 mold was supplied by NIL Technology. This nickel mold contained moth eye nanostructures with a $250 \mathrm{~nm}$ pitch, $300 \mathrm{~nm}$ average height, a peak-to-peak distance of $300 \mathrm{~nm}$ and was supplied with an anti-sticking layer.

\subsection{The Wafer-by-Wafer NIL Process}

The moth eye nanostructures were applied through NIL. The process used consisted of two main steps: preparation of the replica and structuring of the Ormocomp resist, as illustrated in Figure 7.

Figure 7. Schematic process overview of the replica preparation and structuring of the Ormocomp resist.

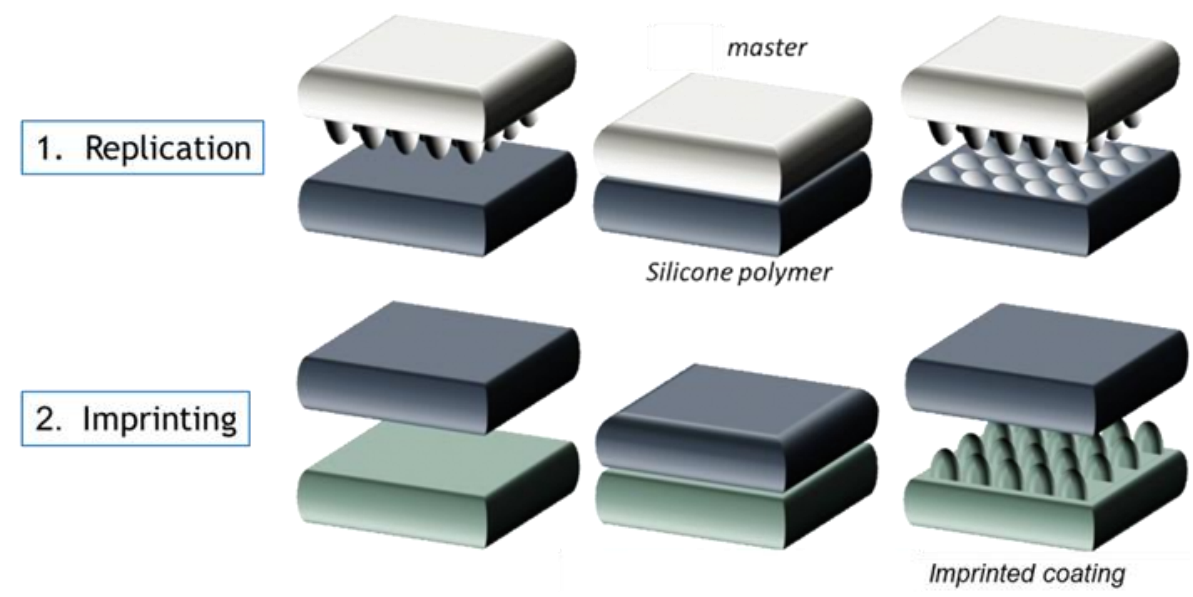

\subsubsection{Preparation of the Replica}

Nanostructure replication into a thin and flexible, UV-transparent silicone polymer was performed using the Holotools HT-AR-09 mold and a stack of two layers of polydimethylsiloxane (PDMS). A first layer of hard PDMS (h-PDMS) was applied on top of the mold. This material has a higher e-modulus compared to regular PDMS, but a much lower elongation at break. The material is quite brittle and requires a bilayer approach, using a second layer of softer PDMS [62].

The h-PDMS mixture was prepared by subsequently adding $30 \mathrm{mg}$ of 1,3,5,7-Tetravinyl-1,3,5,7tetramethylcyclotetrasiloxane, $6.8 \mathrm{~g}$ vinylmethylsiloxane-dimethylsiloxane trimethylsiloxy terminated copolymer, $2 \mathrm{~g}$ (25\%-35\% methylhydrosiloxane) of dimethylsiloxane copolymer and $30 \mathrm{mg}$ of 1,3,5,7-Tetravinyl-1,3,5,7-tetramethylcyclotetrasiloxane. All four components were supplied by ABCR and used without purification. The materials were mixed using a speedmixer at $3500 \mathrm{rpm}$ for $60 \mathrm{~s}$. The h-PDMS was spin coated on top of the mold within 15 min after preparation, at $1000 \mathrm{rpm}$ for $40 \mathrm{~s}$. It was partly cured on a hotplate at $60^{\circ} \mathrm{C}$ for $2 \mathrm{~min}$.

Sylgard 184, supplied by Dow Corning, was used as the soft PDMS material as supplied. It was mixed in a mass ratio of part A:B 10:1 in a speedmixer at $2000 \mathrm{rpm}$ for $60 \mathrm{~s}$. The material was casted on top of the partly cured h-PDMS, until the mold was completely covered with a PDMS layer of approximately $0.5 \mathrm{~mm}$. The stack was cured in a convection oven at $80{ }^{\circ} \mathrm{C}$ for $5 \mathrm{~h}$. The replica was peeled off the mold and used in the NIL process. 


\subsubsection{Structuring of the Ormocomp Resist}

The UV-curable material used for imprinting was Ormocomp, supplied by Micro Resist Technology. It has a 100\% solid content and was used as delivered by the supplier.

Prior to the wet film application, the substrates were dried in a convection oven for $10 \mathrm{~min}$. The oven temperature for PMMA was $80^{\circ} \mathrm{C}$; for PC, $120^{\circ} \mathrm{C}$.

Ormocomp was applied with a $20 \mu \mathrm{m}$ Bird applicator and prebaked in a convection oven at $80{ }^{\circ} \mathrm{C}$ for $15 \mathrm{~min}$. The step-and-flash NIL process was performed using the Nanoimprint Technology Platform from NIL Technology. After the post-exposure bake in a convection oven at $80{ }^{\circ} \mathrm{C}$ for $15 \mathrm{~min}$, the PDMS replica was removed from the sample.

The layer thickness was measured using a standard profilometer.

\subsection{Characterization of Nanostructured Surfaces}

\subsubsection{HIM}

The images were made with the Zeiss Orion Plus HIM. This microscope is located on a special vibrational-free floor and placed in an in-house developed acoustic enclosure. The samples were scanned point by point with a sub-nanometer spot, with an acceleration voltage of $25 \mathrm{kV}$ and a typical beam current between 0.1 and $1 \mathrm{pA}$. The images were recorded with an ET detector, collecting an amount of secondary electrons generated by beam sample interaction. A $5 \mathrm{~nm}$ carbon layer was deposited on the samples prior to analysis.

\subsubsection{AFM}

A Nanosurf Flex AFM with high aspect ratio tips was used in tapping mode for AFM measurements.

\subsection{Optical Characterization}

A Shimadzu UV3600 spectrophotometer was used for total reflection and transmission measurements with an integrating sphere. The incident angle was $7^{\circ}$; the wavelength range was 300 to $1000 \mathrm{~nm}$. The sampling interval was $5.0 \mathrm{~nm}$ and slit width, $20 \mathrm{~nm}$.

\subsection{Scratch Resistance Measurements}

Pencil hardness tests were performed according to ISO15184:1998. In all cases, three substrate samples were coated with Ormocomp resist, moth eye-structured using NIL and cured. $24 \mathrm{~h}$ after preparation, the pencil hardness of the coating was determined on three different positions per sample. Ergo, all values for pencil hardness are average values of nine measurements. In the pencil hardness test, pencils of different hardness ranging from 9B (softest) to 9H (hardest) are moved over a coating surface using a well-defined carrier to guarantee constant weight. Under the applied weight, the soft pencil tips deform more than the harder ones, leading to a larger contact area, $A$. Since the force, $F$, is determined by the weight of the carrier and, therefore, constant, the contact pressure, $p$, changes gradually from low pressure (soft pencils) to high pressure (hard pencils). 


\subsection{Durability Tests}

Three accelerated lifetime tests were performed on PMMA substrates with moth eye-structured Ormocomp, with the non-structured coating and with blank PMMA substrates. Reflection VIS was measured before and after testing. All samples were prepared and tested in triplo.

Three commonly applied accelerated ageing tests were performed: the damp heat test $(1000 \mathrm{~h}$ at $85^{\circ} \mathrm{C}$ and $85 \%$ relative humidity), the thermal cycling test $\left(200\right.$ cycles between $-40{ }^{\circ} \mathrm{C}$ and $\left.85^{\circ} \mathrm{C}\right)$ and the humidity freeze test $\left(10\right.$ cycles between $85^{\circ} \mathrm{C}$ and $85 \%$ relative humidity and $\left.-40{ }^{\circ} \mathrm{C}\right)$.

\section{Conclusions}

In conclusion, we prepared moth eye-structured Ormocomp coatings on PMMA and PC, using a wafer-by-wafer step-and-flash NIL process. The reduction in VIS reflection achieved with these coatings was $3.5 \%$ and $4.0 \%$, respectively. The adhesion of the coating to both substrates was good. The moth eye-structured coating on PMMA demonstrated good performance in three prototypical accelerated ageing tests: the damp-heat, thermal cycling and humidity-freeze test. The pencil hardness of the moth eye-structured Ormocomp coatings on both substrates was $<4 \mathrm{~B}$, which is less than required for most applications and needs further optimization. In addition, we developed a R2R UV NIL pilot scale process and produced moth eye-structured Ormocomp coatings on PET at line speeds up to two meters per minute. The resulting coatings showed a good replication of the moth eye structures and, consequently, a lowering in reflection of the coated PET of 3.0\%. Further optimization of the process is currently ongoing in our laboratories. Ergo, we successfully demonstrated that the two main disadvantages of moth eye-structured graded index ARCs-i.e., the lack of suitable coating materials and a process for large area, high-volume applications - can be eliminated to a large extent, paving the way for cost-efficient and large-scale production of durable nanostructured moth eye-type ARCs on polymer substrates.

\section{Acknowledgments}

We thank Hartmut Fischer (TNO) and Emile van Veldhoven (TNO) for their support in characterization of the moth eye-structured surfaces. Furthermore, we gratefully acknowledge NanoNextNL for its financial support (Program number 9B-17 Large Area Imprint on Flexible Substrates).

\section{Conflicts of Interest}

The authors declare no conflict of interest.

\section{References}

1. MacLeod, H.A.; MacLeod, A. Thin-Film Optical Filters; CRC Press: Bristol, UK, 2001.

2. Chen, D. Anti-reflection (AR) coatings made by sol-gel processes: A review. Sol. Energy Mater. Sol. Cells 2001, 68, 313-336. 
3. Ibn-Elhaj, M.; Schadt, M. Optical polymer thin films with isotropic and anisotropic nano-corrugated surface topologies. Nature 2001, 410, 796-799.

4. Chen, D.; Yan, Y.; Westenberg, E.; Niebauer, D.; Sakaitani, N.; Chaudhuri, S.R.; Sato, Y.; Takamatsu, M. Development of anti-reflection (AR) coating on plastic panels for display applications. J. Sol-Gel Sci. Technol. 2000, 19, 77-82.

5. Schottner, G.; Rose, K.; Posset, U. Scratch and abrasion resistant coatings on plastic lenses-State of the art, current developments and perspectives. J. Sol-Gel Sci. Technol. 2003, 27, 71-79.

6. Gombert, A.; Glaubitt, W.; Rose, K.; Dreibholz, J.; Bläsi, B.; Heinzel, A.; Sporn, D.; Döll, W.; Wittwer, V. Anti-reflective transparent covers for solar devices. Sol. Energy 2000, 68, 357-360.

7. Gombert, A.; Glaubitt, W.; Rose, K.; Dreibholz, J.; Bläsi, B.; Heinzel, A.; Sporn, D.; Döll, W.; Wittwer, V. Subwavelength-structured antireflective surfaces on glass. Thin Solid Films 1999, 351, 73-78.

8. Chen, J.J.; Sun, K.W. Enhancement of the light conversion efficiency of silicon solar cells by using nanoimprint anti-reflection layer. Sol. Energy Mater. Sol. Cells 2010, 94, 629-633.

9. Forberich, K.; Dennler, G.; Scharber, M.C.; Hingert, K.; Fromherz, T.; Brabec, C.J. Performance improvement of organic solar cells with moth eye anti-reflection coating. Thin Solid Films 2008, 516, 7167-7170.

10. Wu, D.; Zhao, Y.B.; Wu, S.Z.; Liu, Y.F.; Zheng, H.; Zhao, S.; Feng, J.; Chen, Q.D.; Ma, D.G.; Sun, H.B. Simultaneous efficiency enhancement and self-cleaning effect of white organic light-emitting devices by flexible antireflection films. Opt. Lett. 2011, 36, 2635-2637.

11. Jeong, S.H.; Kim, J.K.; Kim, B.S.; Shim, S.H.; Lee, B.T. Characterization of $\mathrm{SiO}_{2}$ and $\mathrm{TiO}_{2}$ films prepared using rf magnetron sputtering and their application to anti-reflection coating. Vacuum 2004, 76, 507-515.

12. Kim, J.Y.; Han, Y.K.; Kim, E.R.; Suh, K.S. Two-layer hybrid anti-reflection film prepared on plastic substrates. Curr. Appl. Phys. 2002, 2, 123-127.

13. Glaubitt, W.; Löbmann, P. Antireflective coatings prepared by sol-gel processing: Principles and applications. J. Eur. Ceram. Soc. 2012, 32, 2995-2999.

14. Pénard, L.; Gacoin, T.; Boilot, J.P. Functionalized sol-gel coatings for optical applications. Acc. Chem. Res. 2007, 40, 895-902.

15. Hiller, J.; Mendelsohn, J.D.; Rubner, M.F. Reversibly erasable nanoporous anti-reflective coatings from polyelectrolyte multilayers. Nat. Mater. 2002, 1, 59-63.

16. Du, Y.; Luna, L.E.; Tan, W.S.; Rubner, M.F.; Cohen, R.E. Hollow silica nanoparticles in UV-Visible antireflection coatings for poly(methyl methacrylate) substrates. ACS Nano 2010, 4, 4308-4316.

17. Guillemot, F.; Brunet-Bruneau, A.; Bourgeat-Lami, E.; Gacoin, T.; Barthel, E.; Boilot, J.P. Latex-templated silica films: Tailoring porosity to get a stable low-refractive index. Chem. Mater. 2010, 22, 2822-2828.

18. Huang, Y.F.; Chattopadhyay, S.; Jen, Y.J.; Peng, C.Y.; Liu, T.A.; Hsu, Y.K.; Pau, C.L.; Lo, H.C.; Hsu, C.H.; Chang, Y.H.; et al. Improved broadband and quasi-omnidirectional anti-reflection properties with biomimetic silicon nanostructures. Nat. Nanotechnol. 2007, 2, 770-774.

19. Clapham, P.B.; Hutley, M.C. Reduction of lens reflexion by the 'moth eye' principle. Nature 1973, 244, 281-282. 
20. Kikuta, H.; Toyota, H.; Yu, W. Optical elements with subwavelength structured surfaces. Opt. Rev. 2003, 10, 63-73.

21. Boden, S.A.; Bagnall, D.H. Tunable reflection minima of nanostructured antireflective surfaces. Appl. Phys. Lett. 2008, 93, 133108:1-133108:3.

22. Ai, D.; Lu, W.; Xu, H.; Yang, B.; Huang, C.; Xu, M.; Gao, L.; Weng, Z.; Chi, L. Simple approach to wafer-scale self-cleaning anti-reflective silicon surfaces. Langmuir 2009, 25, 7769-7772.

23. Ting, C.J.; Huang, M.C.; Tsai, H.Y.; Chou, C.P.; Fu, E.C. Low cost fabrication of large-area anti-reflection films from polymer by nanoimprint/hot embossing technology. Nanotechnology 2008, 19, 205501:1-205501:20.

24. Chou, S.Y.; Krauss, P.R.; Renstrom, P.J. Imprint of sub-25 nm vias and trenches in polymers. Appl. Phys. Lett. 1995, 67, 3114-3116.

25. Chou, S.Y.; Krauss, P.R.; Renstrom, P.J. Imprint lithography with $25 \mathrm{~nm}$ resolution. Science 1996, 272, 85-87.

26. Chou, S.Y.; Krauss, P.R.; Renstrom, P.J. Nanoimprint lithography J. Vac. Sci. Technol. B Electron. Nanom. Struct. 1996, 14, 4129-4133.

27. Gates, B.D.; Xu, Q.; Stewart, M.; Ryan, D.; Willson, C.G.; Whitesides, G.H. New approaches to nanofabrication: Molding, printing and other techniques. Chem. Rev. 2005, 105, 1171-1196.

28. Chou, S.Y.; Krauss, P.R.; Zhang, W.; Guo, L.; Zhuang, L. Sub-10 nm imprint lithography and applications. J. Vac. Sci. Technol. B Electron. Nanom. Struct. 1997, 15, 2897-2904.

29. Guo, L.J.; Phys, J. Recent progress in nanoimprint technology and its applications. J. Phys. D Appl. Phys. 2004, 37, R123:1-R123:11.

30. Collburn, M.; Johnson, S.C.; Stewart, M.D.; Damle, S.; Bailey, T.C.; Choi, B.; Wedlake, M.; Michaelson, T.B.; Sreenivasan, S.V.; Ekerdt, J.G.; et al. Step and flash nanoimprint lithography: A new approach to high-resolution patterning. Proc. SPIE 1999, 3676, 379-389.

31. Bailey, T.; Choi, B.J.; Colburn, M.; Heissel, M.; Shaya, S.; Ekerdt, J.G.; Sreenivasan, S.V.; Willson, C.G. Step and flash imprint lithography: Template surface treatment and defect analysis. J. Vac. Sci. Technol. B Electron. Nanom. Struct. 2000, 18, 3572-3577.

32. Menard, E.; Meitl, M.A.; Sun, Y.; Park, J.U.; Shir, D.J.L.; Nam, Y.S.; Jeon, S.; Rogers, J.A. Micro- and nanopatterning techniques for organic electronic and opto-electronic systems. Chem. Rev. 2007, 107, 1117-1160.

33. Khang, D.Y.; Yoon, H.; Lee, H.H. Room-temperature imprint lithography. Adv. Mater. 2001, 13, 749-752.

34. Chen, Y.; Ohlberg, D.A.A.; Li, X.; Stewart, D.R.; Williams, R.S.; Jeppesen, J.O.; Wielsen, K.A.; Stocklart, J.F.; Olynick, D.L.; Andersen, E. Nanoscale molecular-switch devices fabricated by imprint lithography. Appl. Phys. Lett. 2003, 82, 1610-1612.

35. Hoff, J.D.; Cheng, L.J.; Meyhofer, E.; Guo, L.J.; Hunt, A.J. Nanoscale protein patterning by imprint lithography. Nano Lett. 2004, 4, 853-857.

36. Ahn, S.W.; Lee, K.D.; Kim, J.S.; Kim, S.H.; Park, J.D.; Lee, S.H.; Yoon, P.W. Fabrication of a $50 \mathrm{~nm}$ half-pitch wire grid polarizer using nanoimprint lithography. Nanotechnology 2005, 16, 1874:1-1874:9.

37. Guo, L.; Krauss, P.R.; Chon, S.J. Nanoscale silicon field effect transistors fabricated using imprint lithography. Appl. Phys. Lett. 1997, 71, 1881-1883. 
38. Austin, M.D.; Zhang, W.; Ge, H.; Wassermann, D.; Lyon, S.A.; Chou, S.Y. 6 nm half-pitch lines and $0.04 \mu \mathrm{m}^{2}$ static random access memory patterns by nanoimprint lithography. Nanotechnology 2005, 16, 1058:1-1058:8.

39. Truskett, V.N.; Watts, M.P.G. Trends in imprint lithography for biological applications. Trends Biotechnol. 2006, 24, 312-317.

40. Pozzato, A.; Zilio, S.D.; Fois, G.; Vendramin, D.; Misturo, G.; Belotti, M.; Chen, Y.; Natali, M. Superhydrophobic surfaces fabricated by nano-imprint lithography. Microelectron. Eng. 2006, 83, 884-888.

41. Rosnick, D.J.; Dauksher, W.J.; Mancini, D.; Nordquist, K.J.; Bailey, T.C.; Johnsson, S.; Stacey, N.; Ekerdt, J.G.; Willson, C.G.; Sreenivasa, S.V.; et al. Imprint lithography for integrated circuit fabrication. J. Vac. Sci. Technol. B Electron. Nanom. Struct. 2003, 21, 2624-2631.

42. Malyarchuk, V.; Hua, F.; Merck, N.; Velasquez, V.; White, J.; Nuzzo, R.; Rogers, J. High performance plasmonic crystal sensor formed by soft nanoimprint lithography. Opt. Express 2005, 13, 5669-5675.

43. Sun, Y.; Forrest, S.R. Organic light emitting devices with enhanced outcoupling via microlenses fabricated by imprint lithography. J. Appl. Phys. 2006, 100, 073106:1-073106:6.

44. Cho, H.K.; Jang, J.; Choi, J.H.; Choi, J.; Kim, J.; Lee, J.S.; Lee, B.; Choe, Y.H.; Lee, K.D.; Kim, S.H.; et al. Light extraction enhancement from nano-imprinted photonic crystal GaN-based blue light emitting diodes. Opt. Express 2006, 14, 8654-8660.

45. Ferry, V.E.; Verschuuren, M.A.; van Lare, M.C.; Schropp, R.J.; Atwater, H.A.; Polman, A. Optimized spacial correlations for broadband light trapping nanopatterns in high efficiency ultrathin film a-Si: H solar cells. Nano lett. 2011, 11, 4239-4245.

46. Battaglia, C.; Hsu, C.M.; Söderström, K.; Escarré, J.; Hang, F.J.; Charrière, M.; Boccard, M.; Despeisse, M.; Alexander, D.T.L.; Cantoni, M.; et al. Light trapping in solar cells: Can periodic beat random? ACS Nano 2012, 6, 2790-2797.

47. Söderström, K.; Escarré, J.; Cubero, O.; Hang, F.J.; Perregaux, S.; Ballif, C. UV nano-imprint lithography technique for the replication of back reflectors for $\mathrm{n}-\mathrm{i}-\mathrm{p}$ thin film silicon solar cells. Prog. Photovolt. Res. Appl. 2011, 19, 202-210.

48. Jeon, S.; Kong, J.W.; Park, H.D.; Kim, J.J.; Youn, J.R.; Shim, Y.; Jeong, J.H.; Choi, D.G.; Kim, K.D.; Altun, A.O.; et al. Ultraviolet nanoimprinted polymer nanostructure for organic light emitting diode application. Appl. Phys. Lett. 2008, 92, 223307:1-223307:3.

49. Ji, R.; Hornung, M.; Verschuuren, M.A.; Van de Laar, R.; Van Eekelen, J.; Plachetta, U.; Moeller, M.; Moormann, C. UV enhanced substrate conformal imprint lithography (UV-SCIL) technique for photonic crystal patterning in LED manufacturing. Microelectron. Eng. 2010, 87, 936-967.

50. Yanagishita, T.; Nishio, K.; Masuda, H. Anti-reflection structures on lenses by nano-imprinting using ordered porous alumina. Appl. Phys. Express 2009, 2, 022001:1-022001:3.

51. Chang, T.L.; Cheng, K.Y.; Chou, T.H.; Su, C.C.; Yang, H.P.; Luo, S.W. Hybrid-polymer nanostructures forming an anti-reflection film using two-beam interference and ultraviolet nanoimprint lithography. Microelectron. Eng. 2009, 86, 874-877.

52. Chen, Q.; Hubbard, G.; Shields, P.A.; Liu, C.; Allsopp, D.W.E.; Wang, W.N.; Abbott, S. Broadband moth eye antireflection coatings fabricated by low-cost nanoimprinting. Appl. Phys. Lett. 2009, 94, 263118:1-263118:3. 
53. Kim, H.J.; Marcier, A.W.; Garcia, B.; Kwon, D.; Jeffrey, F.; Braymen, S.; Hauschilelt, J.; Taussig, C. Roll-to-roll manufacturing of electronics on flexible substrates using self-aligned imprint lithography (SAIL). J. Soc. Inf. Disp. 2009, 3, 2062-2069.

54. Stuart, C.; Chen, Y. Roll in and roll out: a path to high-throughput nanoimprint lithography. ACS Nano 2009, 3, 2062-2069.

55. Youn, S.W.; Ogiwara, M.; Goto, H.; Takahashi, M.; Maeda, R. Prototype development of a roller imprint system and its application to large area polymer replication for a microstructured optical device. J. Mater. Process. Technol. 2008, 202, 76-85.

56. Seo, S.M.; Kim, T.I.; Lee, H.H. Simple fabrication of nanostructure by continuous rigiflex imprinting. Microelectron. Eng. 2007, 84, 567-572.

57. Han, J.; Choi, S.; Lee, B.S.; Kang, S. Fabrication of transparent conductive tracks and patterns on flexible substrate using a continuous UV roll imprint lithography. J. Phys. D Appl. Phys. 2009, 42, 115503:1-115503:11.

58. Jeans, A.; Almanza-Workman, M.; Cobene, R.; Eleter, R.; Garcia, R.; Golmez-Pancorbo, F.; Jackson, W.; Jam, M.; Kim, H.J.; Kwon, O.; et al. Advances in roll-to-roll imprint lithography for display applications. Proc. SPIE 2010, 7637, 763719:1-763719:12.

59. Moonen, P.F.; Yakimets, I.; Huskens, J. Fabrication of transistors on flexible substrates: from mass printing to high-resolution alternative lithography strategies. Adv. Mater. 2012, 24, 5526-5541.

60. Maury, P.; Turkenburg, D.; Stroeks, N.; Giesen, P.; Barbu, I.; Meinders, E.; Van Bremen, A.; Iosad, N.; Van der Werf, R.; Onvtee, H. Roll-to-roll UV imprint lithography for flexible electronics. Microelectron. Eng. 2011, 88, 2052-2055.

61. Maury, P.; Turkenburg, D.; Stroeks, N.; Giesen, P.; Wijnen, M.; Tacken, R.; Meinders, E.; Van der Werf, R. Roll-to-roll UV imprint for bottom-up transistor fabrication. J. Photopolym. Sci. Technol. 2011, 24, 43-45.

62. Schmid, H.; Michel, B. Siloxane polymers for high-resolution, high-accuracy soft lithography. Macromolecules 2000, 33, 3042-3049.

(C) 2013 by the authors; licensee MDPI, Basel, Switzerland. This article is an open access article distributed under the terms and conditions of the Creative Commons Attribution license (http://creativecommons.org/licenses/by/3.0/). 